\title{
Traffic-Noise Assessment at Rush Hours in Quetta City
}

\author{
Anila Ali, Ali Asghar, Syed Zameer Ul Hassan, Gohram Khan Malghani \\ Faculty of Engineering and Architecture, Balochistan University of Information Technology, \\ Engineering and Management Sciences, Quetta, Balochistan, Pakistan
}

\begin{abstract}
Noise is an environmental stressor, which leads to various ailments due to the physiological and psychological stresses it creates. It is essential to understand and evaluate the contributing factors of environmental noise, especially in densely polluted areas near major roads, railways and airports, for public health policy and planning. Noise level measurement permits precise and scientific analysis of noise annoyance, and therefore, this study aimed to determine the average noise levels of Quetta city. Seventy-three (73) location's equivalent noise levels $\left(L_{e q}\right)$ were measured at peak rush hours for three consecutive days. Selected areas for measurement included health care centres, educational centres, government offices, public places, residential and commercial areas. All the selected sites were located near to main roads, where the traffic noise was the most prominent noise source. Noise was measured through calibrated microprocessor sound level meter. The results were computed by taking the mean of the three readings. The results showed $74 \mathrm{dBA}$ as average noise level of Quetta city. It has been found that $90 \%$ of the selected locations in Quetta city exceeded the 65dBA, while $10 \%$ of the total locations ranged between 55 to $65 \mathrm{dBA}$. The average noise exposure of the Quetta city was greater than the permissible international noise standard. This study identified the main traffic hubs of Quetta city, which requires mitigation strategies by the policy makers specifically for Health care and Educational sectors. It also requires adequate updated plans for community noise survey and ordinance.
\end{abstract}

Keywords- Traffic-noise; Rush hours; environmental stressor; physiological stress; psychological stress.

Date Received 30 Jan 2019

Date Accepted 03 May 2020

Date Published 25 June 2020

\section{INTRODUCTION}

$\mathrm{F}$ rom the public health perspective, noise is regarded as the second highest environmental stressor [1], which is an inevitable pollutant linked with an increased risk of diseases, mainly auditory and non-auditory. A typical auditory effect is hearing impairment, which reduces working concentration, disrupts communications, and increases the likelihood of accidents [2][3]. The nonauditory health effects of noise include cardiovascular diseases [4][5], disturbed sleeping patterns, hypertension [6][7], and mental health deficits such as declining task performance, attention, anxiety, nervousness, fatigue [8][9], annoyance [10], stress hormonal imbalances [11] and reduced health related well-being [12]. Inadequately controlled noise presents a growing danger to the health and welfare of the Nation's population, particularly in urban areas. For public health policy and planning, it is essential to understand and evaluate the contributing factors of environmental noise on health. Environmental noise is ranked second in disability adjusted life years lost (DALYs) in Europe. The DALYs attributed to noise, are more than other pollutants such as lead, ozone and dioxins [13]. Therefore, for policy

Journal of Applied and Emerging Sciences Vol (10), Issue (01) making and planning, it is important to consider noise as an independent factor in contributing to ill-health.

Several studies have been conducted on assessing and analyzing the noise explore of the urban cities, which revealed that the road traffic is typically the largest contributor to community noise (also called environmental noise, residential noise or domestic noise).

Most environmental noise indicators [14] tend to include day values, in form of Day Evening Night Sound Level $\left(\mathrm{L}_{\mathrm{den}}\right)$ or Day-Time $\left(\mathrm{L}_{\mathrm{dn}}\right)$, which means that the equivalent sound level between $7^{\text {th }}$ and $19^{\text {th }}$ hour $\left(L_{d}\right)$ has to be measured, estimated or computed. One of the parameters to describe the noise level is Equivalent Continuous Sound Level ( $\mathrm{L}_{\mathrm{eq}}$ ), measured in decibels (dBA). $L_{\text {eq }}$ is an equivalent to the total sound energy measured over a stated period. There are different measurement techniques such as Day-Time $\left(\mathrm{L}_{\mathrm{dn} / 8}\right)$ noise level computation by traffic noise model. This technique requires realistic traffic data, which is hardly ever available for every single street, therefore, direct noise levels measurements may be the alternative. However, direct, continuous measurement of the Day-Time noise level (equivalent level from 7 am to $7 \mathrm{pm}$ ) is an expensive strategy, if a whole city must be assessed [15]. To overcome this situation, short-term measurements of variable duration are often taken in order to estimate the day-time noise level $\left(\mathrm{L}_{\mathrm{d}}\right)$, because they are less expensive and less resource demanding than continuous measurements over a whole day or more [16]. 


\section{DOI: https://doi.org/10.36785/BUITEMS.JAES.353}

There are different noise standards and regulations provided by different organizations and institutions such as OSHA, HUD, ANSI, ISO, etc. for evaluating the noise assessment. The regulations are based on the type of noise being measured. HUD organization provides the regulations related to the community noise [17].

Noise pollution is a growing problem due to the rapid urbanization in Quetta city. The pollution sources have increased tremendously, which includes factories, markets, social activities and vehicles. Noise assessment and analysis is a powerful diagnostic tool for formulating noise reduction programs from airports, railways, main roads and sectors that requires quieter surroundings. There is a scarcity of literature displaying traffic noise pollution in Quetta city, therefore, this study aimed at measuring the average noise levels (dBA) of different locations of the city at peak hours. This study would draw attention to the threat of noise pollution in Quetta city and would encourage the regulatory agencies to control noise at its source.

\section{MATERIALS AND METHODS}

\section{A. Study Population}

Area-wise, district Quetta ranked 4th smallest district in Balochistan and has an area of 2,653 square kilometers. Quetta District lies between $66^{\circ} 41^{\prime} 40^{\prime \prime}-67^{\circ} 17^{\prime} 25^{\prime \prime}$ East longitudes and $30^{\circ} 01^{\prime} 29^{\prime \prime}-30^{\circ} 28^{\prime} 25^{\prime \prime}$ North latitudes. It consists 2 Tehsils including Zarghoon and Chiltan with subdivision of 37 and 30 union councils respectively. Location of Quetta is at $690 \mathrm{~km}$ (aerial distance) south-west (237degrees bearing) of Pakistan's capital city, Islamabad. According to the census of 2017, the Quetta District has a population of 1,001,205 [18]. For the purpose of noise measurement and mapping in this study, Quetta city was divided into different sectors. The division mainly represents both the Thesils, which covers major densely polluted areas of the Quetta city.

Some sectors are characterized as those areas which requires quieter environment. It included educational and health care centers, with recommended noise levels less than $50 \mathrm{dBA}$ as per criterium of National Environmental Quality Standards for Noise [19]. In this sector, Health Care centers (8) and Educational centers (11) were selected from different points of the city. Besides the above-mentioned sectors, those areas which does not certify any noise limitation above 50 included government offices (9), public places (8), residential areas (14) and commercial areas (23).

\section{B. Instrument}

Microprocessor SL-5826, Sound Level Meter was used for the measurement of noise levels. The instrument specification includes frequency ranged in between $31.5 \mathrm{~Hz}$ to $8 \mathrm{KHz}$, noise measurement ranged in between 35 to $130 \mathrm{dbA}$, while detection characteristics were fast, slow and peak hold. The accuracy of instrument was $\pm 0.5 \mathrm{dBA}$ with the precision of $0.1 \mathrm{dBA}$. The calibrated instrument was obtained from the Baluchistan Environment Protection Agency (BEPA).

\section{Procedure}

The noise level measurement was carried out at seventy-three locations spread across all the urban areas in the community of Quetta city. The noise levels were measured at three peak hours, which included 08:00 am, 02:00 pm and 06:00 pm for 15 minutes. Each area's noise levels were collected for three consecutive days. The process of measurements was restricted only to weekdays i.e. from Monday to Friday, in order to observe the uniformity in the traffic and community noise on working days and always under ideal meteorological conditions (no wind or rain). The noise level measurements were carried out over the period of 5 months.

The Sound Level Meter was placed at a location 2 meters ( 6.5 feet) in the direction of the predominant noise (arterial and main road) surrounding (as according to HUD exterior criteria of noise assessment). For the noise assessment of the Public places and Residential sectors, google map was consulted to identify the central point. This procedure was adapted for the identified locations of Quetta city, as according to the recommendation in the paper by Romeu and collaborators [15].

The Sound Level Meter was calibrated to $130 \mathrm{dBA}$ before each measurement. The maximum noise level was measured with the instrument set at "Fast" detection feature. After the noise monitoring session, the instrument was post calibrated after the transfer of data into spreadsheet. After the noise measurements were carried out from 73 areas, the data was transferred to the Sound Level Meter software. Later the data was tabulated and logged on Excel worksheet for calculation of means, maximum and minimum recorded noise levels and was classified on the criterium of HUD community noise levels and National Environmental Quality Standards for Noise.

The environmental noise of Quetta city was evaluated on the criteria of National Environmental Quality Standards for Noise provided by Pakistan Environmental Protection Agency Act, 1997 (XXXIV of 1997) [19]. Table 1 lists the external noise levels as a function of the type of land use and period (daytime or nighttime) according to the National Environmental Quality Standards for Noise. The results were also evaluated on the International standards of Community Noise, such as HUD community standards, which described noise up to $65.0 \mathrm{dBA}$ as "Acceptable", $65.0 \mathrm{dBA}$ to $75.0 \mathrm{dBA}$ as "Normally Unacceptable" and above $75.0 \mathrm{dBA}$ as "Unacceptable" [17].

\section{TABLE I}

National Environmental Quality Standards for Noise established by Pakistan Environmental Protection Agency

\begin{tabular}{cccc}
\hline Sr.No. & $\begin{array}{c}\text { Category of zone/ } \\
\text { area }\end{array}$ & \multicolumn{2}{c}{ Limits in dBA Leq } \\
\cline { 3 - 4 } & Day-Time & $\begin{array}{c}\text { Night-Time } \\
6.00 \mathrm{am} \text { to } \\
10.00 \mathrm{pm}\end{array}$ & $\begin{array}{c}10.00 \mathrm{pm} \text { to } \\
6.00 \mathrm{am}\end{array}$ \\
\hline $\mathbf{1}$ & Residential Area & 55 & 45 \\
\hline $\mathbf{2}$ & Commercial Area & 65 & 55 \\
\hline $\mathbf{3}$ & $\begin{array}{c}\text { Industrial } \\
\text { Area }\end{array}$ & 75 & 65 \\
\hline $\mathbf{4}$ & $\begin{array}{c}\text { Silence } \\
\text { zone* }\end{array}$ & 50 & 45 \\
\hline
\end{tabular}




\section{RESULTS AND DISCUSSION}

Table 2 shows the results of minimum and maximum average noise exposure of seventy-three locations at three Peak hours. The minimum noise level for Health Care sector was $70 \mathrm{dBA}$ at 08:00 am, while for educational sector, it was 72 dBA at 08:00 am. The overall results showed minimum and maximum average noise levels valued between 59 and $89 \mathrm{dBA}$, respectively in the Quetta city.

TABLE 2

Minimum and Maximum Noise Levels (dBA) of selected Sectors, Quetta City

\begin{tabular}{|c|c|c|c|c|c|c|c|}
\hline \multirow[t]{2}{*}{ Sectors } & \multirow{2}{*}{$\begin{array}{l}\text { No. of } \\
\text { Areas }\end{array}$} & \multicolumn{3}{|c|}{$\begin{array}{l}\text { Minimum Average } \\
\text { Noise Levels (dBA) }\end{array}$} & \multicolumn{3}{|c|}{$\begin{array}{l}\text { Maximum Average } \\
\text { Noise Levels (dBA) }\end{array}$} \\
\hline & & $\begin{array}{l}8 \\
\mathrm{am}\end{array}$ & $\begin{array}{l}2 \\
\mathrm{pm}\end{array}$ & $\begin{array}{l}6 \\
\mathrm{pm}\end{array}$ & $\begin{array}{l}8 \\
\mathrm{am}\end{array}$ & $\begin{array}{l}2 \\
\mathrm{pm}\end{array}$ & $\begin{array}{l}6 \\
\mathrm{pm}\end{array}$ \\
\hline $\begin{array}{r}\text { Health care } \\
\text { centers }\end{array}$ & 8 & 70 & 71 & 71 & 78 & 80 & 81 \\
\hline $\begin{array}{r}\text { Educational } \\
\text { centers }\end{array}$ & 11 & 72 & 74 & 73 & 88 & 87 & 84 \\
\hline $\begin{array}{r}\text { Government } \\
\text { offices }\end{array}$ & 9 & 63 & 69 & 66 & 85 & 84 & 86 \\
\hline $\begin{array}{l}\text { Public } \\
\text { places }\end{array}$ & 8 & 68 & 70 & 68 & 83 & 82 & 85 \\
\hline $\begin{array}{r}\text { Commercial } \\
\text { areas }\end{array}$ & 23 & 66 & 69 & 70 & 84 & 89 & 89 \\
\hline $\begin{array}{r}\text { Residential } \\
\text { areas }\end{array}$ & 14 & 60 & 60 & 59 & 79 & 80 & 81 \\
\hline
\end{tabular}

Fig. 1 shows the comparison of average noise exposure (dBA) among different sectors in Quetta city. The average noise exposure of Quetta city based on 73 locations was $74 \mathrm{dBA}$. The highest average noise exposure $(80.0 \mathrm{dBA})$ was recorded at the Educational sectors $(n=11)$, followed by Commercial areas $(n$ $=23$ ) with $78.0 \mathrm{dBA}$, Health locations $(n=8)$ with $77 \mathrm{dBA}$, government offices $(n=9)$ and Public places $(n=8)$ with76 dBA and Residential area $(n=14)$ with $67.0 \mathrm{dBA}$. The results evidently showed that the exterior noise exposure in Quetta city exceeds $67 \mathrm{dBA}$, which exceeds the permissible noise levels at peak hours, according to international standards and the National Environmental Quality Standards for Noise.

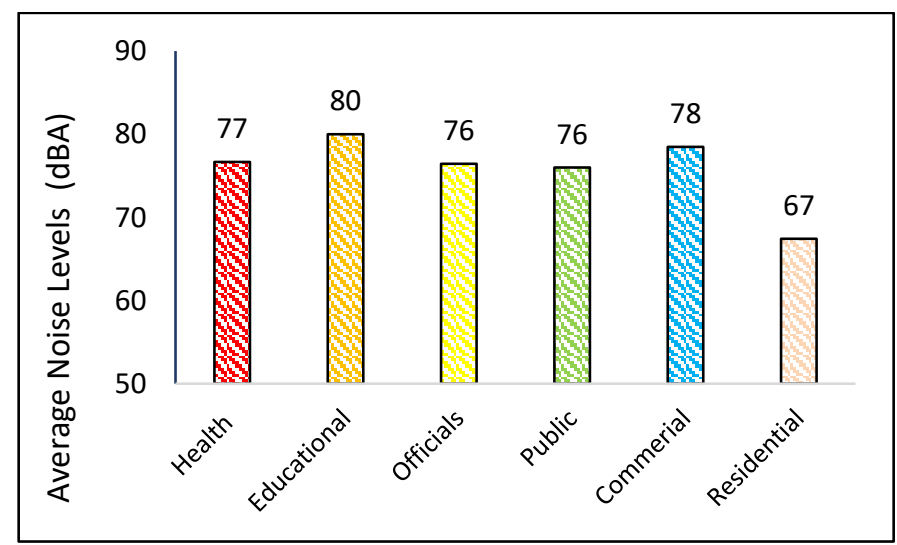

Fig. 1. Comparison of Average Noise Levels (dBA) among different Sectors in Quetta city

\section{A. Health Care Centers}

Fig. 2 shows the equivalent sound level values (Leq) of the Journal of Applied and Emerging Sciences Vol (10), Issue (01) noise measured at peak hours of all the health care centers. The comparison across the three peak hours showed that the highest noise exposure was observed during 06:00 pm $($ Mean $=78$ $\mathrm{dBA}, \mathrm{SD}=3)$ followed by 02:00 $\mathrm{pm}($ Mean $=77 \mathrm{dBA}, \mathrm{SD}=$ 2.9 ) and then at 08:00 am (Mean $=75 \mathrm{dBA}, \mathrm{SD}=2.1)$. The minimum average noise level among Health locations was 70 $\mathrm{dBA}$ and maximum were $81 \mathrm{dBA}$. National Environmental Quality Standards for Noise (as shown in Table 1) establishes a maximum value of Leq $=50 \mathrm{dBA}$ as the criterion for noise exposure in outdoor environments, particularly in Silence zone, which includes hospitals, educational centers and zones which are declared as such by the competent authority. An analysis of the noise measurements at peak hours of health sites also indicates that noise levels exceeds to maximum at 06:00 pm, which is usually the doctors private visiting hours. All these hospitals are located at the main streets and resides with commercial and residential areas.

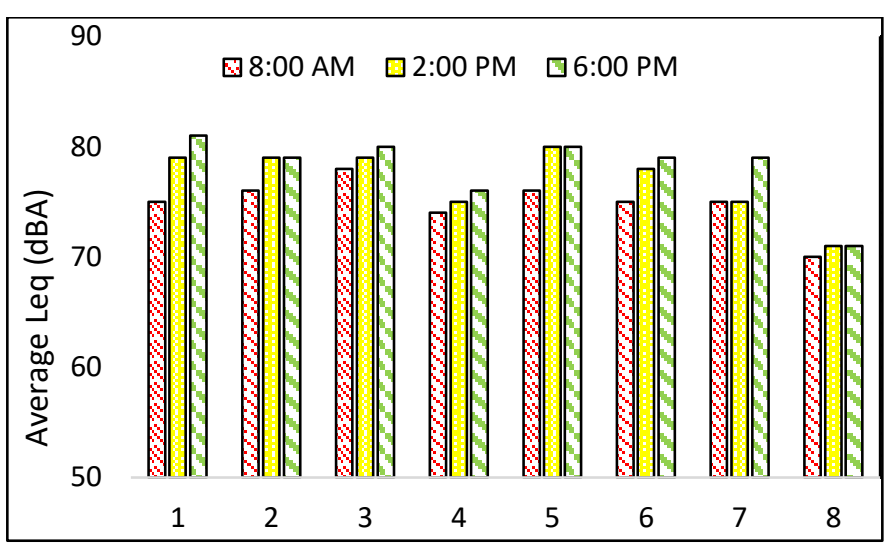

Fig. 2. Comparison of Leq (dBA) of Health care sector at three Peak hours Note: 1: Sendamen Provincial Hospital, 2: Akhram Hospital, 3: Quetta Hospital, 4: Mid East Hospital,5: Saleem Complex,6: Haji Sangeen Khan Hospital,7: Quetta Diagnostic Center,8: Fiaz Laboratory.

\section{B. Educational Centers}

Fig. 3 shows the equivalent sound level values $\left(\mathrm{L}_{\mathrm{eq}}\right)$ of the noise measured at peak hours from all the selected locations of Educational sector. The comparison across the three peak hours shows that the highest noise exposure was observed during 08:00 am $($ Mean $=81 \mathrm{dBA}, \mathrm{SD}=4.4), 02: 00 \mathrm{pm}($ Mean $=81$ $\mathrm{dBA}, \mathrm{SD}=3.4)$ and then at 06:00 $\mathrm{pm}($ Mean $=78 \mathrm{dBA}, \mathrm{SD}=$ 3.6). The minimum and maximum average noise level among Educational locations was $72 \mathrm{dBA}$ and $88 \mathrm{dBA}$ respectively. As mentioned earlier, National Environmental Quality Standards for Noise (as shown in Table 1) has established a maximum value of Leq at $50 \mathrm{dBA}$ as the criterion for noise exposure in outdoor environments, particularly in Silence zones. The noise assessment of all the educational institutes at three peak hours presents Equivalent Sound Level $\left(\mathrm{L}_{\mathrm{eq}}\right)$ above $50 \mathrm{dBA}$. An analysis of the noise measurements at peak hours of Educational sites also indicates that noise levels exceeds to maximum at 08:00 am and then at 02:00 pm, which are usually the door off and pick-up timings of the educational institutes. The systematic review by Schubert [20] has evaluated an adverse effect of transportation noise on behavioral and emotional disorders in children and adolescents. They further 
concluded declined results in cognitive performance, emotional and behavioral disorders in children and adolescences even at relatively low environmental noise levels around schools and educational centers. Therefore, protective policy could therefore be more effective if focused at the school level.

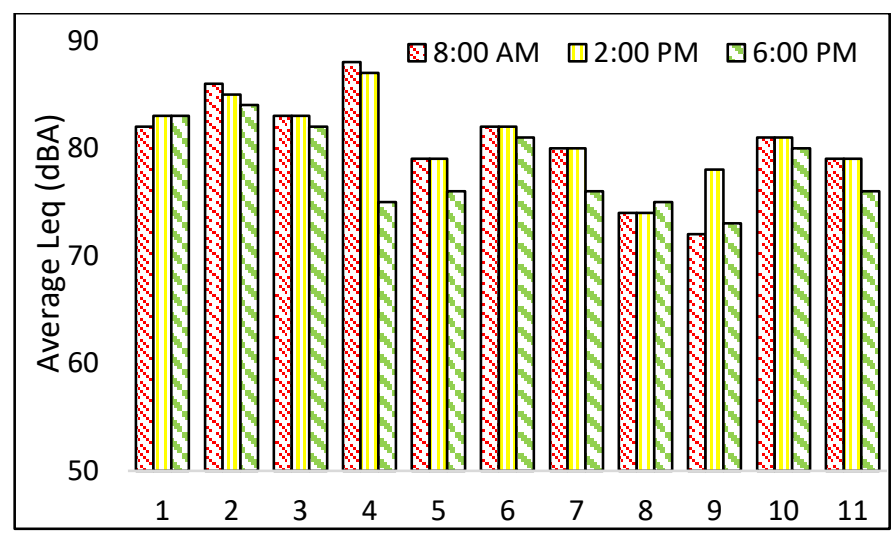

Fig. 3. Comparison of Leq (dBA) of Educational Sector at three Peak hours Note: 1: Saint Joseph's Convent High School, 2: Islamia Girls High School, 3: Special High School, 4: Beacon House School, 5: Govt Girls College Cannt,6: Helper High School, 7: BUITEMS City Campus, 8: BUITEMS

Takkutu Campus, 9: Pearl Institute, 10: City School Jinnah Town, 11: Govt Sendamen High School.

\section{Government Offices}

Fig. 4 shows the equivalent sound level values (Leq) at peak hours of selected government offices. The comparison across the three peak hours shows that the highest noise exposure was observed during 02:00 pm (Mean $=78 \mathrm{dBA}, \mathrm{SD}=4.3$ ), followed by 08:00 am (Mean $=76 \mathrm{dBA}, \mathrm{SD}=6.3)$ and then at 06:00 pm (Mean $=76 \mathrm{dBA}, \mathrm{SD}=5.8)$. The minimum and maximum average noise level among Officials was $63 \mathrm{dBA}$ and $86 \mathrm{dBA}$, respectively. The government offices, as being the custodial of public policy and planning, qualifies to exist under the silence zone as described by the National Environmental Quality Standards for Noise. However, measurements from this study at peak hours showed Equivalent sound level above recommended limits. The noise measurements at peak hours of official sites showed maximum values at 02:00 pm and then at 06:00 pm. However, the increase in noise levels at locations 2 and 5 at 08:00 am can be attributed to presence of schools in those locations that tends to increase the traffic flow. It can also be observed that the locations constituted on main junctions and arterial roads had higher noise levels (dBA) as compared to the others.

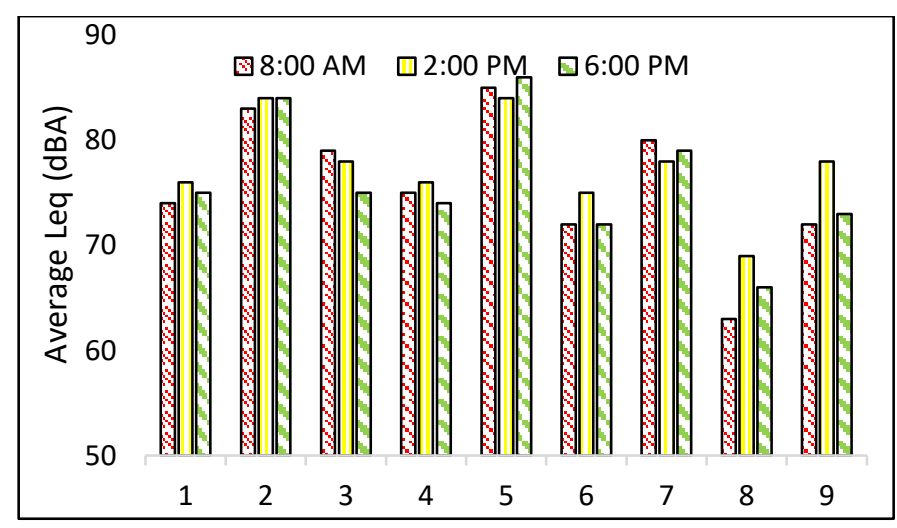

Journal of Applied and Emerging Sciences Vol (10), Issue (01)
Fig. 4. Comparison of Leq (dBA) of government offices at three peak hours NOTE: 1: Sectriate Block three,2: Balochistan High Court, 3: Balochistan Lower Court,4: NADRA, 5: GPO, 6: Askari Bank Meazan Chowk, 7: Passport Office, 8: PIA Office, 9: Pakistan Telecommunication LTD.

\section{Public Places}

Fig. 5 shows the equivalent sound level values $\left(\mathrm{L}_{\mathrm{eq}}\right)$ of the noise measured at peak hours of all the selected public places. The comparison across the three peak hours shows that the highest noise exposure was observed during 06:00 pm (Mean = $77 \mathrm{dBA}, \mathrm{SD}=5.3$ ), followed by 08:00 am (Mean $=75 \mathrm{dBA}, \mathrm{SD}$ $=5.4)$ and then at $02: 00 \mathrm{pm}($ Mean $=75 \mathrm{dBA}, \mathrm{SD}=4.1)$. The minimum and maximum average noise level were $68 \mathrm{dBA}$ and $85 \mathrm{dBA}$, respectively. For comparison of measured noise of public locations with National Environmental Quality Standards for Noise (as shown in Table 1), maximum value of $\mathrm{L}_{\mathrm{eq}} 65 \mathrm{dBA}$ is allowed as per their commercial criterion. The measured equivalent sound level values for all locations at three peak hours exceeds the criterion limit. The noise measurements at peak hours showed noise levels exceeded maximum at 06:00 $\mathrm{pm}$ because of evening activities of the citizens and then at 02:00 pm. The noise levels of location 7 are exceeding $80 \mathrm{dBA}$, which is probably due to the presence of congested arterial road surrounded with hospitals and commercial shops. It can also be observed that the locations constituted on main junctions had higher noise levels.

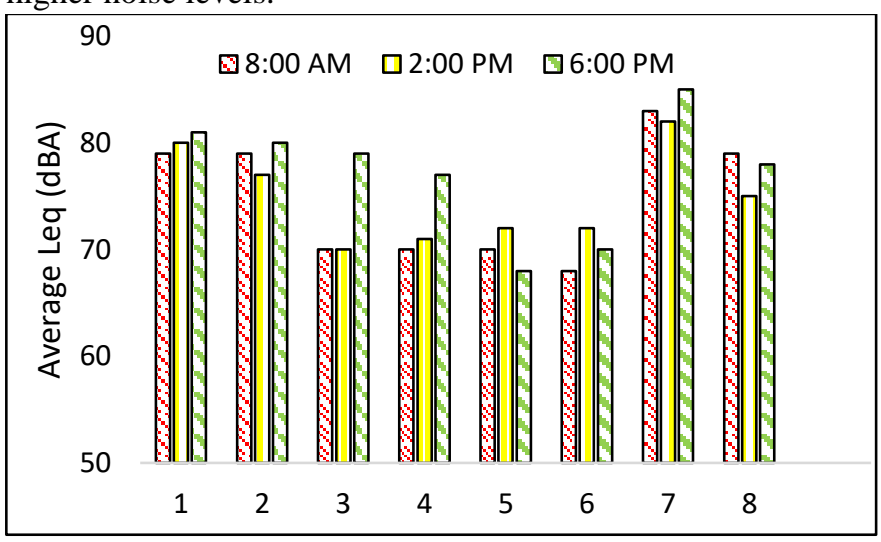

Fig. 5. Comparison of Leq (dBA) of public places at three Peak hours NOTE: 1: Ziarat park, 2: Railway Station, 3: Ladies park, 4: Askari park, 5: Airport, 6: Imdad cinema, 7: Saddabahar bus terminal, 8: Liaquat park.

\section{E. Commercial Areas}

Fig. 6 shows the equivalent sound level values (Leq) of the noise measured at Peak hours of all the selected commercial centers. The comparison across the three peak hours shows that the highest noise exposure was observed during 06:00 pm $($ Mean $=80 \mathrm{dBA}, \mathrm{SD}=4.9)$, followed by 02:00 $\mathrm{pm}($ Mean $=79$ $\mathrm{dBA}, \mathrm{SD}=4.9)$ and then at 08:00 $\mathrm{am}$ (Mean $=77 \mathrm{dBA}, \mathrm{SD}=$ 5.0). The minimum and maximum average noise level among commercial centers were $66 \mathrm{dBA}$ and $89 \mathrm{dBA}$, respectively. According to National Environmental Quality Standards for Noise (as shown in Table 1) maximum value of $\mathrm{L}_{\mathrm{eq}} 65 \mathrm{dBA}$ is stated as the criterion for noise exposure in outdoor environments for commercial areas. The average equivalent sound level values of all locations in this study at peak hours is 
exceeding the stated criterion. The noise measurements at peak hours of commercial sites showed noise levels exceeded maximum at 06:00 pm and then at 02:00 pm, which particularly reflects the evening social activities. It can be observed from the Figure 6 that the locations which has lower noise levels (dBA), as compared to other locations, either exists on quite zones e.g. Bolan Welfare (cantonment). The traffic speed is being regularly monitored and does not exceed the stated speed limit at these locations. The locations where equivalent sound levels are maximum were constituted on multiple main junctions or wide arterial roads with no stated speed limits, while the others lie on congested roads with very slow traffic flow.

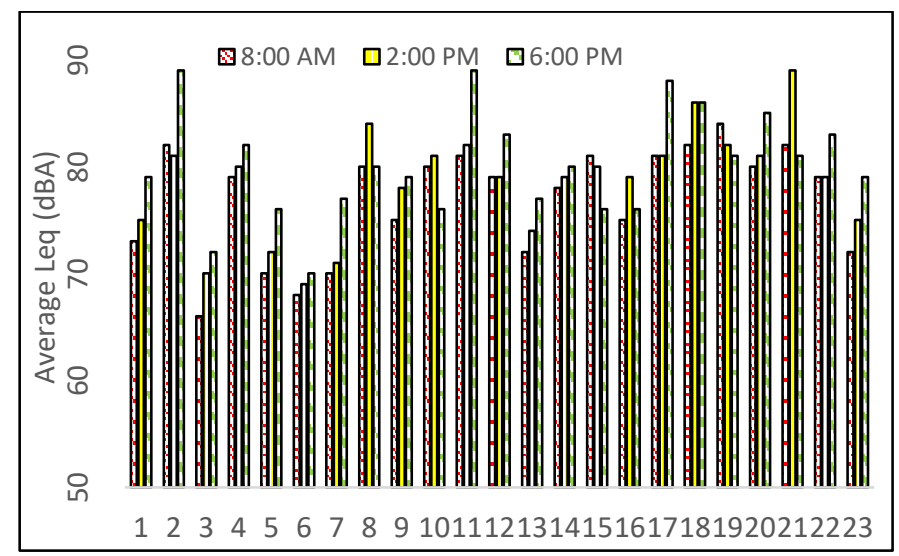

Fig. 6. Comparison of Leq (dBA) of Commercial Sector at three Peak Hours NOTE: 1: Dawood Center, 2:Pashin Stop, 3: Bolan Welfare 4: Suraj Gang Bazar, 5: Liaquat Bazar, 6: Fateh Khan Market, 7: Mini Market Satelite Town, 8: Meazah Chowk, 9: Masjid Road, 10: Brewery Road, 11: AlmoChowk, 12: Askhari Pump Zarghoon Road, 13: Prince Road, 14: Vegetable Market Kasi Road, 25: Sirki Road, 16: Double Road,17: Farhan Road, 18: PSO Pump Airport Road, 19: Millennium Mall, 20: Grain Silios, Airport Road 21: Joint Road, 22: Zarghoon Road 23: Food Point Samungli Road

\section{F. Residential Areas}

Fig. 7 shows the equivalent sound level values (Leq) of the noise measured at peak hours of all the selected residential locations. The comparison across the three peak hours showed that the highest noise exposure was observed during 08:00 am $($ Mean $=68 \mathrm{dBA}, \mathrm{SD}=5.9)$, followed by 02:00 $\mathrm{pm}($ Mean $=68$ $\mathrm{dBA}, \mathrm{SD}=6.3)$ and then at 06:00 $\mathrm{pm}($ Mean $=67 \mathrm{dBA}, \mathrm{SD}=$ 6.9). The minimum and maximum average noise level among residential areas was $59 \mathrm{dBA}$ and $81 \mathrm{dBA}$, respectively. According to National Environmental Quality Standards for Noise (as shown in Table 1) maximum value of $\mathrm{L}_{\mathrm{eq}} 55 \mathrm{dBA}$ is set as the criterion for noise exposure in outdoor environments in residential locations. However, the findings of this study indicate that the equivalent noise exposure of residential locations are above $55 \mathrm{dBA}$ at all three peak hours. An analysis of the noise measurements at peak hours of residential areas showed that noise level varied among the locations at peak hours, since many residential areas include educational centers, government offices and commercial centers in their surroundings. Residential locations whose maximum equivalent noise level was observed at 08:00am and 02.00pm had educational centers and government offices, while those locations where maximum equivalent noise level was observed at 6:00 pm had commercial centers.

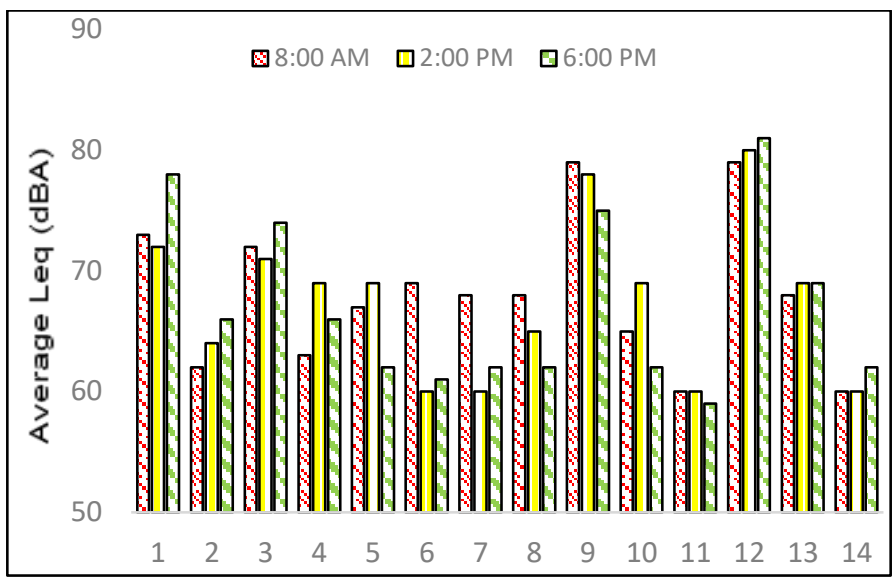

Fig. 7. Comparison of Leq (dBA) of residential areas at three Peak Hours. NOTE: 1: Satellite Town Block one, 2: Shabaaz Town Phase One, 3: Mecongi Road, 4:Madrassa Road, 5: Chiltan Housing Scheme, 6: Chaman Housing Scheme, 7: Model Town Phase One, 8: Wahdat Colony, 9: Fatima Jinnah Road, 10: Marriabad, 11: Jinnah town, 12: Zarghoon Road, 13: Toghi Road, 14: Gulistan Road.

The distribution of the measured average equivalent sound level values $\left(\mathrm{L}_{\mathrm{eq}}\right)$ of three peak hours across all locations $(\mathrm{n}=$ 73) are shown in Table 3. A plot of the percentage of the mean values in different locations is shown in Fig. 8. According to HUD community standards, noise not exceeding $65.0 \mathrm{dBA}$ is "Acceptable". From our sample locations, there were only 7 locations (10\%) which did not exceed 65 dBA. Whereas, 6 locations (8\%) were above $66 \mathrm{dBA}$ and 18 locations $(25 \%)$ were below $75 \mathrm{dBA}$, which are considered as "Normally Unacceptable" under the category of "Acoustically Undesirable Areas". While 25 (34\%) and 17 (23\%) locations are above 76 and 81 , respectively, which are considered as "Unacceptable Area". Therefore, it can be concluded that $90 \%$ of the selected locations in Quetta city are above $65 \mathrm{dBA}$ and $10 \%$ of the total locations peak hours ranges between 55 to $65 \mathrm{dBA}$.

According to the European Union (EU), about $40 \%$ of the EU population was exposed to road traffic noise in excess of 55 $\mathrm{dBA}, 20 \%$ was exposed to more than $65 \mathrm{dBA}$ in the daytime, and $30 \%$ was exposed to more than $55 \mathrm{dBA}$ during the night in 2011. The EU predicts that the population exposed to excess noise will continue to increase over time [21].

TABLE 3

Distribution of measured Leq (dBA) values in 73 locations spread all over urban areas of Quetta city

\begin{tabular}{ccc}
\hline Range of measured Leq & No. of locations & Percentage $(\%)$ \\
\hline Leq $<55$ & 0 & 0 \\
\hline $55<$ Leq $<60$ & 2 & 3 \\
\hline $61<$ Leq $<65$ & 5 & 7 \\
\hline $\mathbf{6 6}<$ Leq $<70$ & 6 & 25 \\
\hline $71<$ Leq $<75$ & 18 & 34 \\
\hline $76<$ Leq $<80$ & 25 & 23 \\
\hline $81<$ Leq $<85$ & 17 & 0 \\
\hline$<$ Leq $>86$ & 0 & 8 \\
\hline
\end{tabular}




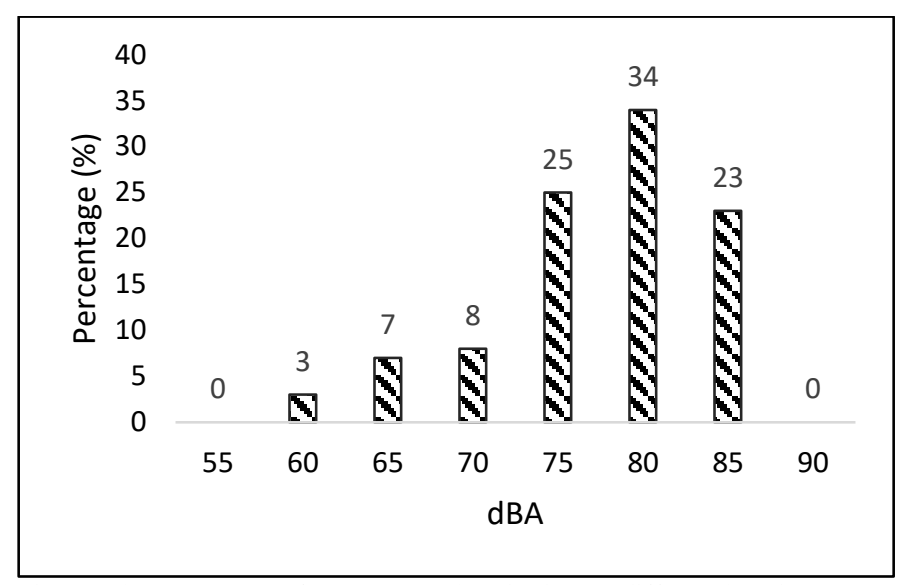

Fig. 8. The percentage of mean Leq values in $\mathrm{dBA}$ at different locations

The overall findings of the noise measurements at selected locations in Quetta city, at peak hours, revealed excessive noise levels as per the standard values according to HUD and National Environmental Quality Standards for Noise (Pakistan). The excessive noise levels, above the standards, can have an adverse effect on the psychological and physiological health of the citizens of the city. Several community, environmental, and traffic noise-based studies have significantly associated poor degraded health status in the presence of excessive noise [22-24]. Studies also suggests that noise sensitive people are more prone to negative impact on their quality of life with high intensity and exposures of noise [25]. Noise also increases the likelihood of other non-auditory health effects, that can cause discomfort and stress, lower daytime labor productivity, and increase the likelihood of developing cardio cerebrovascular diseases such as hypertension and myocardial infarction [26].

Environmental Protection Agency of Pakistan (EPA) is a regulatory body concerning the environmental issues, however, it has not devised or formulated any noise standards for measurement and analysis of noise pollution. In this study, the method of noise measurement and noise levels of various places in Quetta city has been presented, moreover, various international standards, procedures and relevant studies are also quoted.

Assessing noise levels in large cities can be challenging due to the dense population and variety of noise sources contributing to the acoustic environment [27] and can contribute to non-auditory health problems [28]. Therefore, the limitation of the study was the safety of instrument's installation, at nearly all locations, for 8-hourly and 24-hourly Day-Night Sound Levels $\left(\mathrm{L}_{\mathrm{dn}}\right)$ measurements. For further studies, it is recommended to measure $\mathrm{L}_{\mathrm{dn}}$ of the Quetta city to provide vivid scenario of noise pollution. Outdoor yearly DayNight Sound Levels $\left(\mathrm{L}_{\mathrm{dn}}\right)$ measurements would provide indepth analysis to protect public health and welfare if it exceeds $55 \mathrm{dBA}$ in sensitive areas such as residences, schools, hospitals, etc.

Noise is said to be an environmental stressor [1], which requires attenuation and mitigation strategies. Therefore, this study has highlighted the importance of regulating the land use patterns for housing and other noise sensitive area needs (such as educational and health care centres) that requires a suitable separation between them and major noise sources. New regulations are needed to guide and support the construction of ssites exposing to unacceptable noise and the noise assessment in populated areas to ensure the comfort of the community.

\section{CONCLUSIONS}

In this paper, we have presented basic noise measurements of Quetta city at three peak hours. The results revealed high noise levels at places, which otherwise, are considered as silence zones according to the international and national standards. Total $10 \%$ of locations were below $65 \mathrm{dBA}$, whereas, $90 \%$ of the locations exceeded the equivalent noise level standards at peak hours. It can be concluded that during the working hours, the city in general is exposed to noise levels of up to $81 \mathrm{dBA}$. Such high levels of noise are unacceptable for living purposes and the status of noise pollution in Quetta city is a cause of concern. To reduce the noise pollution problem in Quetta city, the following is proposed; putting barriers and allowing enough spaces between residential areas and noise sources; limiting the exposure time; setting up community noise surveys and ordinances for adequate plans to noise control programs. This study has further highlighted the importance of legislation and policy making from various tiers and government agencies. By implementing noise control laws and more tolerable urban noise levels, enhancement of healthy and productive urban environment in Quetta city can be achieved.

\section{REFERENCES}

[1] Kim R. Burden of disease from environmental noise. WHO International Workshop on Combined Environmental Exposure: Noise, Air Pollutants and Chemicals. Ispra, 2007.

[2] Kirchner, D. Bruce, Eric Evenson, Robert A. Dobie, Peter Rabinowitz, James Crawford, Richard Kopke, and T. Warner Hudson, "Occupational noise-induced hearing loss: ACOEM task force on occupational hearing loss," Journal of occupational and environmental medicine, vol. 54, pp. 106-108, 2012.

[3] Fredriksson, Sofie, Oscar Hammar, Kjell Torén, Artur Tenenbaum, and Kerstin Persson Waye, "The effect of occupational noise exposure on tinnitus and sound-induced auditory fatigue among obstetrics personnel: a cross-sectional study," BMJ open, vol. 5, pp. e005793, 2015.

[4] Guo, Liqiong, Peng-hui Li, Hua Li, Elena Colicino, Silvia Colicino, Yi Wen, Ruiping Zhang et al. "Effects of environmental noise exposure on DNA methylation in the brain and metabolic health," Environmental research, vol. 153, pp. 73-82, 2017.

[5] Girard, Serge Andre, Tony Leroux, René Verreault, Marilene Courteau, Michel Picard, Fernand Turcotte, Julie Baril, and Olivier Richer, "Cardiovascular disease mortality among retired workers chronically exposed to intense occupational noise," International archives of occupational and environmental health, vol. 88, pp. 123-130, 2015.

[6] Kawada, Tomoyuki, "Noise and health-Sleep disturbance in adults," Journal of occupational health, vol. 53, pp. 413-416, 2011.

[7] Wang, Shuai, Qizhong Qin, Lu Liu, Lingli Han, and Yu Chen, "A cross-sectional study on the effects of occupational noise exposure on hypertension or cardiovascular among workers from automobile manufacturing company of Chongqing, China," Journal of Biomedical Science and Engineering, vol. 6, pp. 1137, 2013.

[8] Jahncke, Helena, Staffan Hygge, Niklas Halin, Anne Marie Green, and Kenth Dimberg, "Open-plan office noise: Cognitive performance and restoration," Journal of Environmental Psychology, vol. 31, pp. 373-382, 2011. 
[9] Ali, Anila, and Roslinah Mohamad Hussain, "Cognitive Impairment among Young Motorcyclists: A controlled study," EnvironmentBehaviour Proceedings Journal, vol. 3, pp. 321-329, 2018.

[10] Atmaca, E., I. Peker, and A. Altin, "Industrial Noise and Its Effects on Humans," Polish Journal of Environmental Studies, vol. 14, pp. 721-6, 2005.

[11] Selander, Jenny, Gösta Bluhm, Töres Theorell, Göran Pershagen, Wolfgang Babisch, Ingeburg Seiffert, Danny Houthuijs et al., "Saliva cortisol and exposure to aircraft noise in six European countries," Environmental health perspectives, vol. 117, no. 11, pp. 1713-1717, 2009.

[12] Fyhri, Aslak, and Ronny Klæboe, "Road traffic noise, sensitivity, annoyance and self-reported health-A structural equation model exercise," Environment International, vol. 35, pp. 91-97, 2009.

[13] Hänninen, Otto, Anne B. Knol, Matti Jantunen, Tek-Ang Lim, André Conrad, Marianne Rappolder, Paolo Carrer et al., "Environmental burden of disease in Europe: assessing nine risk factors in six countries," Environmental health perspectives, vol. 122, pp. 439-446, 2014.

[14] Annex IV, Annex V, Annex VI. The Proposed Environmental Liability Directive. European Environmental Law Review. 2002 Nov:315.

[15] Phan, Hai Yen Thi, Takashi Yano, Hai Anh Thi Phan, Tsuyoshi Nishimura, Tetsumi Sato, and Yoritaka Hashimoto, "Community responses to road traffic noise in Hanoi and Ho Chi Minh City," Applied Acoustics, vol. 71, pp. 107-114, 2010.

[16] Romeu, J., M. Genescà, T. Pàmies, and S. Jiménez, "Street categorization for the estimation of day levels using short-term measurements," Applied acoustics, vol. 72, pp. 569-577, 2011.

[17] Environmental Protection Agency, Curitiba, Lei Municipal 8583, 1995.

[18] "Provisional summary results of 6th population and housing census2017 | pakistan bureau of statistics". www.pbs.gov.pk.

[19] Environmental standards and laws, Ministry of Environment http://www.env.go.jp/en/lar/regulation/noise.html

[20] Schubert, Melanie, Janice Hegewald, Alice Freiberg, Karla Romero Starke, Franziska Augustin, Steffi G. Riedel-Heller, Hajo Zeeb, and Andreas Seidler, "Behavioral and emotional disorders and transportation noise among children and adolescents: a systematic review and meta-analysis," International journal of environmental research and public health, vol. 16, pp. 3336, 2019.

[21] World Health Organization. Burden of disease from environmental noise: Quantification of healthy life years lost in Europe. World Health Organization. Regional Office for Europe, 2011.

[22] Riedel, Natalie, Heike Köckler, Joachim Scheiner, and Klaus Berger, "Objective exposure to road traffic noise, noise annoyance and self-rated poor health-framing the relationship between noise and health as a matter of multiple stressors and resources in urban neighbourhoods," Journal of Environmental Planning and Management, vol. 58, pp. 336-356, 2015.

[23] Oiamo, Tor H., Isaac N. Luginaah, and Jamie Baxter, "Cumulative effects of noise and odour annoyances on environmental and health related quality of life," Social Science \& Medicine, vol. 146 pp.191203, 2015.

[24] Shepherd, Daniel, David Welch, Kim N. Dirks, and David McBride, "Do quiet areas afford greater health-related quality of life than noisy areas?," International journal of environmental research and public health, vol. 10, pp. 1284-1303, 2013.

[25] Ali, Anila, Roslinah M. Hussain, Nazri C. Dom, and Razi Ikhwan Md Rashid, "A profile of noise sensitivity on the health-related quality of life among young motorcyclists," Noise \& health, vol. 20, pp. 53, 2018.

[26] Fyhri, Aslak, and Gunn Marit Aasvang, "Noise, sleep and poor health: Modeling the relationship between road traffic noise and cardiovascular problems," Science of the Total Environment, vol. 408, pp. 4935-4942, 2010.

[27] Givargis, Sh, and H. Karimi, "A basic neural traffic noise prediction model for Tehran's roads," Journal of Environmental Management, vol. 91, pp. 2529-2534, 2010.

[28] Ali, Anila, Nazri Che Dom, Roslinah Mohamad Hussain, Subramaniam Karuppannan and Mujid Abdullah, "Auditory Profile of Undergraduate University Motorcyclists: Prevalence of Hearing Loss and Hearing Impairment," EnvironmentAsia, vol. 11 pp. 217 229, 2018.

Journal of Applied and Emerging Sciences Vol (10), Issue (01)

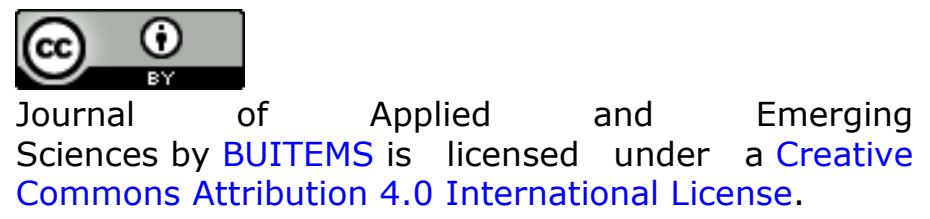
Commons Attribution 4.0 International License. 